\title{
Real-time seismic intensity prediction using frequency-dependent site amplification factors
}

\author{
Masashi Ogiso $^{1 *}$, Shigeki Aoki ${ }^{2}$ and Mitsuyuki Hoshiba ${ }^{1}$
}

\begin{abstract}
A promising approach for the next generation of earthquake early warning system is based on predicting ground motion directly from observed ground motion, without any information of hypocenter. In this study, we predicted seismic intensity at the target stations from the observed ground motion at adjacent stations, employing two different methods of correction for site amplification factors. The first method was frequency-dependent correction prediction, in which we used a digital causal filter to correct the site amplification for the observed waveform in the time domain. The second method was scalar correction, in which we used average differences in seismic intensity between two stations for the site amplification correction. Results from thousands of station pairs that covered almost all of Japan showed that seismic intensity prediction with frequency-dependent correction prediction was more accurate than prediction with scalar correction. Frequency-dependent correction for site amplification in the time domain may lead to more accurate prediction of ground motion in real time.
\end{abstract}

Keywords: Site amplification factor, Real-time correction, Seismic intensity prediction, Earthquake early warning

\section{Introduction}

One of the main purposes of earthquake early warning (EEW) is to predict strong ground motion for a locality before seismic waves arrive on the basis of limited ground motion observation. Most existing EEW systems rely on rapid estimation of earthquake source parameters (origin time, latitude, longitude, depth, and magnitude) which are then fed to a ground motion prediction equation (GMPE). In these EEW systems summarized by Wenzel and Zschau (2014), two key issues are precise estimation of source parameters and the precision of the GMPE. For the first issue, the 2011 Tohoku earthquake (M9.0) showed that rapid estimation of source parameters is hampered by very large focal areas and the simultaneous occurrence of aftershocks (Hoshiba et al. 2011; Hoshiba and Ozaki 2013). Attempts to solve the problem of large focal areas have included analysis of real-time

\footnotetext{
*Correspondence: mogiso@mri-jma.go.jp

${ }^{1}$ Meteorological Research Institute, Japan Meteorological Agency, 1-1 Nagamine, Tsukuba, Ibaraki 305-0052, Japan

Full list of author information is available at the end of the article
}

GNSS data (e.g., Colombelli et al. 2013; Grapenthin et al. 2014) and direct estimation of focal area and rupture direction directly from observed seismograms (Böse et al. 2012). Other ingenious methods have been proposed to distinguish simultaneous multiple earthquakes (e.g., Tamaribuchi et al. 2014; Wu et al. 2014). The second issue of precision of GMPEs depends strongly on the influence of site amplification (e.g., Midorikawa 2009). Because site amplification generally shows frequency dependency (e.g., Satoh and Kawase 2009), many studies have attempt to estimate frequency-dependent site amplification factors from observed waveforms (e.g., Phillips and Aki 1986; Kawase and Matsuo 2004; Ikeura and Kato 2011; Takemoto et al. 2012; Nakano et al. 2015). On the other hand, in many GMPEs, where the variable to be predicted is the peak ground acceleration or peak ground velocity, site amplification effects are corrected by a scalar value (e.g., Midorikawa 2009). Ground motion predictions with frequency-dependent site amplification have been made (e.g., Nozu et al. 2007; Hata et al. 2011); however, their use in real-time (EEW) system is rare. 
Recently, Hoshiba (2013a) proposed that ground motion could be predicted directly from observed ground motion observations in real time by using the Kirchhoff-Fresnel integral theorem, avoiding difficulties in estimating hypocentral parameters and improving the prediction accuracy of ground motion in EEW. In this approach, real-time simulation of wave propagation uses the observed wavefield, not the hypocentral parameters, as the initial condition. Correction of site amplification remains important in this scheme, and Hoshiba (2013b) proposed the use of digital causal filters that can be applied in a real-time setting for the correction.

In this study, we explored the new concept of Hoshiba (2013a) by attempting to predict ground motion at a target station from the observed waveforms of an adjacent station. If the distance between two stations is small compared with the epicentral distance, interstation differences in ground motion are mainly due to differences in the site amplification factor. In such a case, we can predict the ground motion at a target station from the waveforms of the adjacent station by applying site amplification correction. In this paper, we conduct seismic intensity prediction experiments at a target station from observed waveforms from an adjacent station in two methods and compare them. We used seismic intensity scale defined by the Japan Meteorological Agency (JMA seismic intensity) as the predicted variable of ground motion. JMA seismic intensity is calculated from threecomponent acceleration waveforms (JMA 1996; Hoshiba and Ozaki 2013).

\section{Experimental methods of seismic intensity prediction}

We used two different methods to predict seismic intensity at a target station from observed waveforms of an adjacent station in real time. Our underlying assumption was that the differences in seismic intensities between the two stations arise mainly from differences in their site amplification factors. Our two prediction methods differed in their correction for site amplification.

The first method used frequency-dependent correction. If we know the frequency-dependent site amplification factor at both stations, we can adjust the site amplification term of one station to that of the other station through deconvolution and convolution of the site amplification term. Correction of the site amplification term allows us to derive the predicted waveforms at the second station from those of the first. We can then calculate seismic intensity from the predicted waveforms. Usually, deconvolution and convolution of the site amplification term are done in the frequency domain. However, Hoshiba (2013b) proposed a real-time convolution and deconvolution technique employing digital causal filters in the time domain, which we adopted for this study.

The second method used scalar correction. If many earthquakes have been recorded at both of two adjacent stations, we can calculate the average differences in seismic intensity between the stations. To predict seismic intensity at one station, we simply add that average difference (a scalar value) to the seismic intensity at the other station.

Although JMA seismic intensity is operationally calculated in the frequency domain, we adopted the procedure proposed by Kunugi et al. (2013) for real-time calculation of JMA seismic intensity in the time domain. This allowed both of our prediction methods to be applied in real time, as is required for EEW.

\section{Estimation of frequency-dependent site amplification factors}

To predict seismic intensity for two adjacent stations, we do not have to know the absolute site amplification term of either station, only the relative site amplification factor between them is required. Consider the case where an earthquake is observed at two stations. If the epicentral distance is large compared with the interstation distance, we can neglect the small difference in the source terms at each station and attribute the differences in amplitude to the relative site amplification factor and differences in the path term. Ikeura and Kato (2011) used this approach to calculate spectral ratios of direct S-waves for many station pairs, and they estimated relative site amplification factors with respect to a reference station by solving the relevant equations simultaneously. We took the similar approach in this study.

The observed amplitude of a seismic waveform at the $i$ th station for the $k$ th earthquake in the frequency domain can be expressed as follows:

$$
O_{i k}(f)=R_{i k} \cdot S_{k}(f) \cdot T_{i k}(f) \cdot G_{i}(f),
$$

where $O_{i k}(f)$ is the observed amplitude, $R_{i k}$ is the radiation pattern between the $i$ th station and the $k$ th earthquake, $S_{k}(f)$ is the source term, $T_{i k}(f)$ is the path term, and $G_{i}(f)$ is the site amplification factor at station $i$. Consider the case in which adjacent two stations $i$ and $j$ observe earthquake $k$, where the hypocentral distances of each station are long compared with the distance between the stations. In such a case, we can assume that the radiation pattern and source term at both stations are almost the same, so that the observed spectral ratio between stations $i$ and $j$ is expressed by the following path and site terms:

$$
\frac{O_{i k}(f)}{O_{j k}(f)} \approx \frac{T_{i k}(f)}{T_{j k}(f)} \cdot \frac{G_{i}(f)}{G_{j}(f)} .
$$

The ratio of path terms $T_{i k}(f) / T_{i k}(f)$ is expressed by 


$$
\frac{T_{i k}(f)}{T_{j k}(f)}=\frac{r_{j k}}{r_{i k}} \exp \left(-\frac{\pi f}{Q(f) \beta}\left(r_{i k}-r_{j k}\right)\right),
$$

where $Q(f)$ means the frequency-dependent intrinsic attenuation factor of the medium, $\beta$ is the seismic velocity of the medium, and $r_{i k}, r_{j k}$ are the hypocentral distances from the $k$ th earthquake to each station, respectively. Substituting Eq. (3) into Eq. (2) and taking a common logarithm, we can get the relationship between site amplification factors of two stations,

$\log _{10} \frac{G_{i}(f)}{G_{j}(f)}=\log _{10}\left\{\frac{O_{i k}(f)}{O_{j k}(f)} \frac{r_{i k}}{r_{j k}} \exp \left(\frac{\pi f}{Q(f) \beta}\left(r_{i k}-r_{j k}\right)\right)\right\}$.

In this study, we used $4.0 \mathrm{~km} / \mathrm{s}$ for the seismic velocity of medium $\beta$. To avoid the influences of the $Q(f)$ to the spectral ratios, Ikeura and Kato (2011) calculated a sophisticated weighted average of observed spectral ratios (left-hand side of Eq. 4) without any assumption of the $Q(f)$ value. However, we adopt the $Q(f)$ value based on Satoh et al. (1994):

$$
Q(f)= \begin{cases}110 f^{0.69} & (f \geq 1.0 \mathrm{~Hz}) \\ 110 & (f<1.0 \mathrm{~Hz})\end{cases}
$$

for the correction of the influences of the $Q(f)$.

On the other hand, the relative site amplification factor for two station, $G_{i}(f) / G_{i}(f)$, can be rewritten by using the site amplification factors relative to a common reference station:

$$
\frac{G_{i}(f)}{G_{j}(f)}=\frac{G_{i}(f) / G_{r e f}(f)}{G_{j}(f) / G_{r e f}(f)}=\frac{G_{i / r e f}(f)}{G_{j / r e f}(f)},
$$

where $G_{r e f}(f)$ is the site amplification factor at the reference station and $G_{i / r e f}(f), G_{j / r e f}(f)$ are the relative site amplification factors at stations $i$ and $j$ with respect to the reference station. Substituting Eq. (6) to Eq. (4), we get the linear relationship

$$
\begin{aligned}
& \log _{10} G_{i / r e f}(f)-\log _{10} G_{j / r e f}(f) \\
& \quad=\log _{10}\left\{\frac{O_{i k}(f)}{O_{j k}(f)} \frac{r_{i k}}{r_{j k}} \exp \left(\frac{\pi f}{Q(f) \beta}\left(r_{i k}-r_{j k}\right)\right)\right\} .
\end{aligned}
$$

The right-hand side of Eq. (7) is evaluated by using the observed waveforms, so that we can set up simultaneous equations with unknown parameters, $\log G_{i / r e f}(f)$ and $\log G_{j / r e f}(f)$, and solve these equations by a least-squares method.

\section{Estimation of digital filters}

We built digital filters that approximate site amplification characteristics ("site-correct filters" hereafter) based on Hoshiba (2013b). Site amplification characteristics are modeled by combinations of first-order and second-order analog filters:

$$
\begin{aligned}
F(s)= & G_{0} \prod_{n=1}^{N}\left(\frac{\omega_{2 n}}{\omega_{1 n}}\right)\left(\frac{s+\omega_{1 n}}{s+\omega_{2 n}}\right) \cdot \prod_{m=1}^{M}\left(\frac{\omega_{2 m}}{\omega_{1 m}}\right)^{2} \\
& \times\left(\frac{s^{2}+2 h_{1 m} \omega_{1 m} s+\omega_{1 m}^{2}}{s^{2}+2 h_{2 m} \omega_{2 m} s+\omega_{2 m}^{2}}\right)
\end{aligned}
$$

where $N$ and $M$ are the numbers of first- and second-order filters, $\omega_{1 n}, \omega_{2 n}, \omega_{1 m}, \omega_{2 m}$ are the angular frequencies and $h_{1 m}, h_{2 m}$ are the damping factors that determine the frequency characteristics, $G_{0}$ is the gain factor, and $s=i(2 \pi f)$.

After modeling the site amplification characteristics in Eq. (8), digital filters are designed by using bilinear transform and prewarping techniques. Digital filters that correspond to Eq. (8) are expressed generally in the form:

$$
\begin{aligned}
F(z)= & g_{0} \prod_{n=1}^{N}\left(\frac{a_{0 n}+a_{1 n} z^{-1}}{1+b_{1 n} z^{-1}}\right) \\
& \cdot \prod_{m=1}^{M}\left(\frac{a_{0 m}+a_{1 m} z^{-1}+a_{2 m} z^{-2}}{1+b_{1 m} z^{-1}+b_{2 m} z^{-2}}\right),
\end{aligned}
$$

where $s$ and $z$ satisfy the following equation:

$$
s=\frac{1-z^{-1}}{1+z^{-1}} .
$$

Coefficients of the digital filters are calculated from the angular frequencies, damping factors, and the gain factor in Eq. (8) and from the sampling interval of the time series, $\Delta T$. Inverse filters, which correspond to the deconvolution of site amplification at a station, are derived by the reciprocal of Eq. (8). These site-correct filters satisfy causality and can be applied in the time domain.

\section{Procedures for estimating frequency-dependent site amplification}

For our estimates of site amplification, we used data from the strong-motion stations of the Kyoshin Network (K-NET) and Kiban Kyoshin Network (KiK-net) operated by the National Research Institute for Earth Science and Disaster Prevention (NIED, Okada et al. 2004). KiKnet stations have two sensors, one at the surface and the other in a borehole. We treated these as the different stations. We collected waveforms from these two networks since May 1996 to May 2014, excluding March and April 2011 to avoid the high seismicity related to the 2011 Tohoku earthquake (Hirose et al. 2011). While a part of KiK-net records have sampling frequency of $200 \mathrm{~Hz}$, sampling frequency for the most of records is $100 \mathrm{~Hz}$. We picked station pairs that were less than $30 \mathrm{~km}$ apart, 
and calculated spectral ratios from the station records of earthquakes between 100 and $350 \mathrm{~km}$ from both stations, to satisfy the assumption of a shared source term. We excluded the records which had a peak ground acceleration value over $100 \mathrm{gal}(100 \mathrm{~cm} / \mathrm{s} / \mathrm{s})$ to avoid influences of nonlinear behavior of medium to the observed waveforms. The time window for the direct $\mathrm{S}$-wave record was $20.48 \mathrm{~s}$, starting $2 \mathrm{~s}$ before the theoretical S-wave travel time as calculated from hypocentral information in the JMA unified earthquake catalog and the JMA2001 travel time table (Ueno et al. 2002). Time window of $20 \mathrm{~s}$ length might be appropriate for duration time of direct $\mathrm{S}$-wave for our data set. After applying a $5 \%$ cosine taper to the resulting waveforms, we calculated Fourier spectra (with a $0.4 \mathrm{~Hz}$ Parzen window) for the time window from the three components of the seismometer record using fast Fourier transform. Spectra of the horizontal component were vector sums of the NS and EW components. We then calculated the path-corrected spectral ratios (righthand side of Eq. 7) for each station pair, treating vertical and horizontal components separately. To reduce the variation in the path-corrected spectral ratios, we averaged them from at least seven earthquakes for each station pair in a logarithmic scale. Then, we set up simultaneous equations (Eq. 7) with one reference station in each frequency. We selected borehole sensor at IBRH19 (KiKnet Tsukuba, see Fig. 1) as the reference station, because the sensor on the borehole is located in the layer with the $\mathrm{S}$-wave velocity of about $2.8 \mathrm{~km} / \mathrm{s}$. Solving the simultaneous equations (Eq. 7) for both vertical and horizontal components, we obtained the site amplification factors relative to the reference station.
We then modeled these site amplification factors by using analog filters (Eq. 8). The number of filters, $N$ and $M$, was restricted to values from 0 to 6 , ruling out the case $N=M=0$. We estimated the filter parameters $\omega_{1}$ ${ }_{n}, \omega_{2 n}, \omega_{1 m}, \omega_{2 m}, h_{1 m}, h_{2 m}, G_{0}$ by a least-squares method for each combination of $N$ and $M$ and selected the combination that had minimum residuals. Residuals were calculated for the frequency range of $0.05-20 \mathrm{~Hz}$. Finally, we calculated the coefficients of the digital filters (Eq. 9) from the parameters of the analog filters (Eq. 8).

\section{Estimation result of site amplification factors and site-correct filters}

We calculated spectral ratios of adjacent stations using the records of 5574 earthquakes (Fig. 1). We set up the simultaneous equations with the station pairs which shared at least one station with other pairs and then solved them by a least-squares method. Figure 2 shows the station distribution of (a) successfully estimated and (b) not estimated of site amplification factors and sitecorrect filters. Stations that we had estimated site amplification factors cover almost whole area of Japan, with the exception of northernmost Hokkaido, the northern part of Kyushu, and outlying islands.

\section{Waveform prediction using site-correct filters}

As an example of the predicted waveforms using site-correct filters, Fig. 3 shows the case for the large earthquake of 25 March 2007 (M6.9 in JMA scale), observed at stations FKI006 (K-NET Imajoh) and surface station of FKIH05 (KiK-net Tsuruga). The two stations are $21 \mathrm{~km}$ apart, and epicentral distance to FKI006 is about 166 km (Fig. 3a).

\section{a Epicenters}

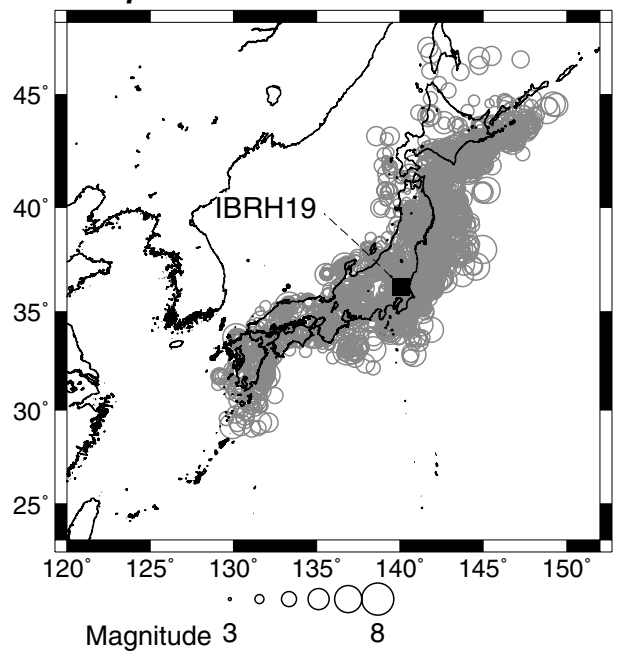

b Magnitude-frequency

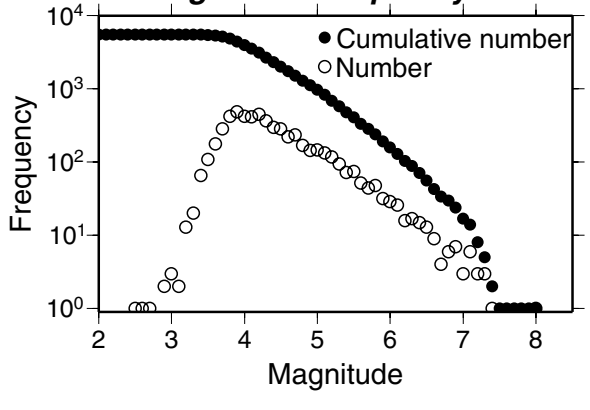

Fig. 1 a Epicenters and $\mathbf{b}$ magnitude-frequency relation (open circle for number and black for cumulative number) of earthquakes used for calculation of spectral ratios. Reference station (IBRH19, KiK-net Tsukuba) is shown as a black square on a 


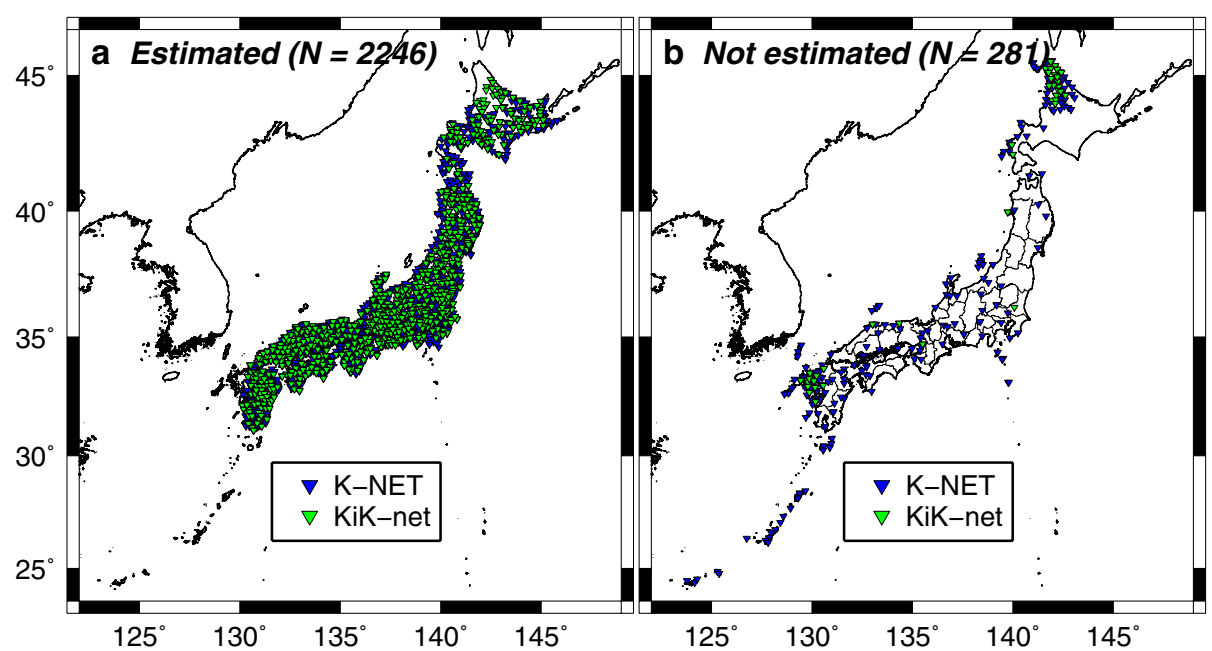

Fig. 2 Distribution of stations for which site amplification factors and site-correct filters were $\mathbf{a}$ successfully estimated and $\mathbf{b}$ not estimated

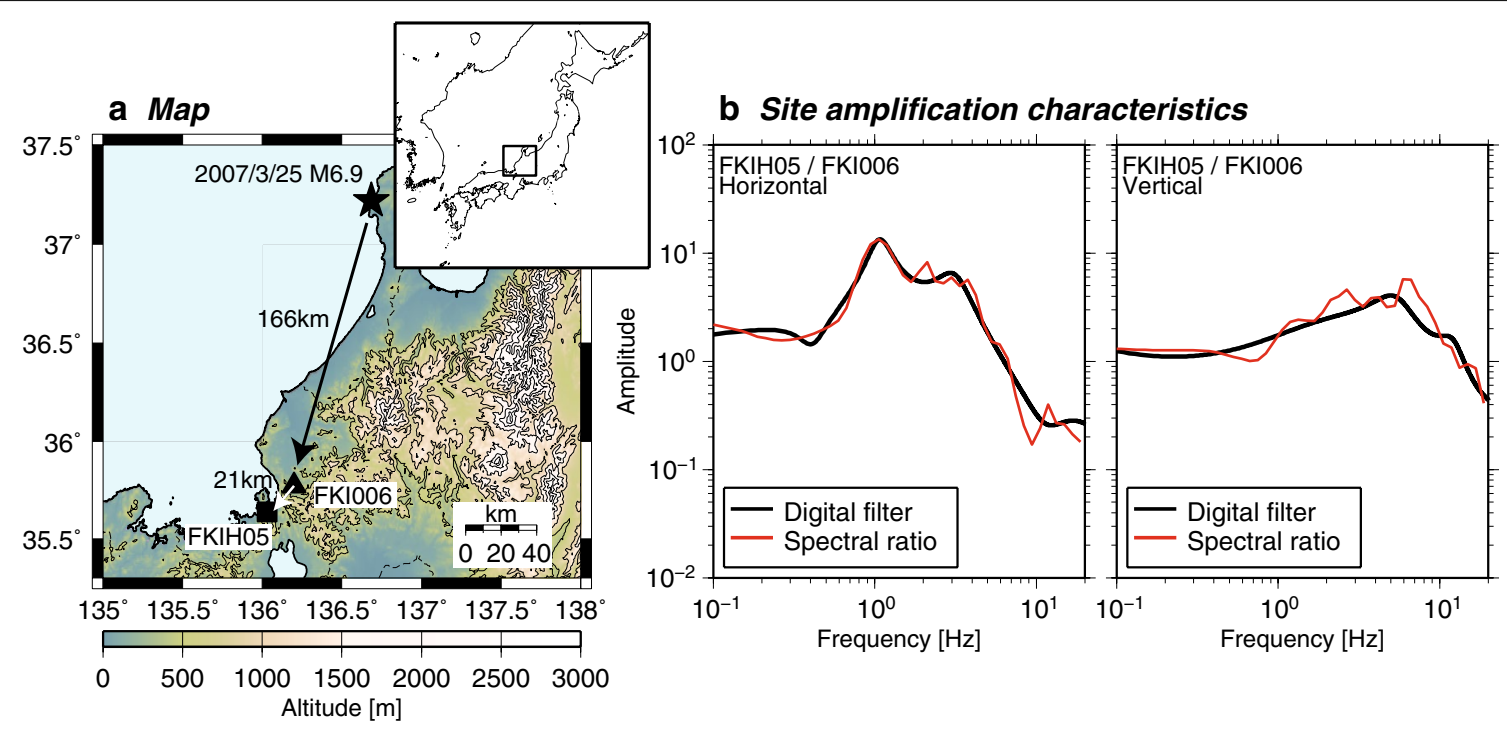

Fig. 3 a Locations of the 25 March 2007 earthquake epicenter and two stations (FKI006: K-NET Imajoh and FKIH05: KiK-net Tsuruga). Contour interval is $500 \mathrm{~m}$. b Relative site amplification factors between stations FKI006 and FKIH05 (surface) by spectral ratio (red) and site-correct filter methods (black)

The site amplification factors between these two stations, calculated from the site-correct filters and observed spectral ratios, are quite similar for both horizontal and vertical records (Fig. 3b). Note that the phase characteristics of the site-correct filters are determined by the condition of causality, so that phase characteristics between the two stations were not included in this waveform calculation.

The observed waveforms of the 25 March 2007 earthquake at stations FKI006 and FKIH05 (surface) are shown in Fig. 4a, b, respectively. Under the assumption that the source term is the same at the two stations, the waveforms reflect differences in the path and site terms. Figure 4c shows the waveforms at FKI006 after its site terms were replaced with those of FKIH05 (surface), so that we can regard these waveforms as predicted waveforms of FKIH05. The predicted waveforms are much more similar to the observed waveforms at FKIH05, in both the time and frequency domains, than the observed waveforms at FKI006 even without correcting for differences in the path term. 
a FKI006 (observed) 2007/3/25 M6.9
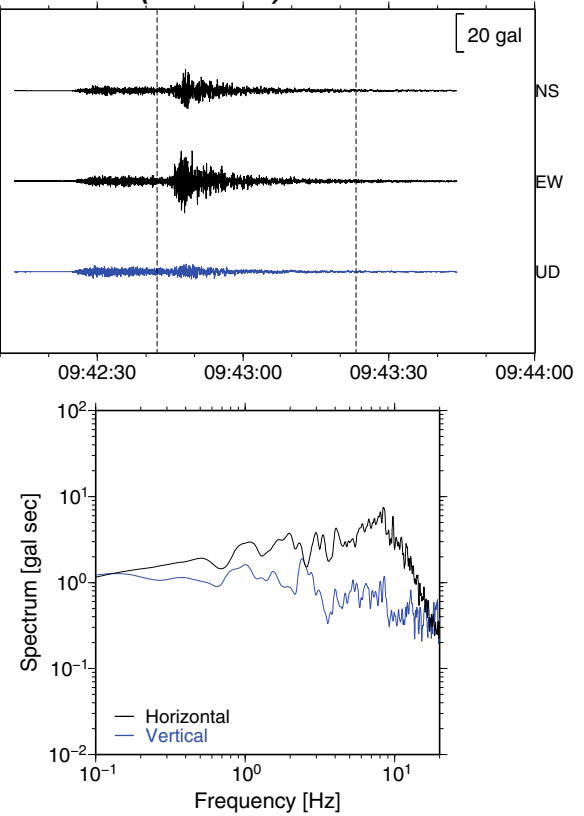

C FKIHO5 (from FKI006) 2007/3/25 M6.9
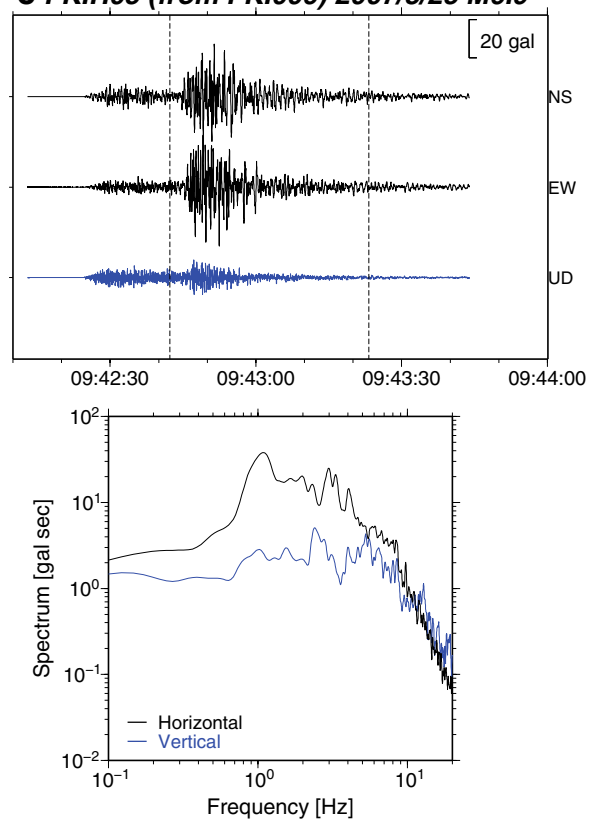

Fig. 4 Waveforms and their spectra from a observations at station FKI006, b observations at station FKIH05 (surface), and c site-corrected waveforms at station FKIH05 (surface) based on observations at station FKI006. Dotted lines represent the 40.96-s time window used for spectrum calculation

\section{Comparison of two intensity prediction methods}

To compare the seismic intensity prediction results of the frequency-dependent and scalar correction methods, we selected station pairs that were separated by less than $10 \mathrm{~km}$. We did not predict seismic intensity at sensors on the borehole of KiK-net stations in these b FKIHO5 (observed) 2007/3/25 M6.9
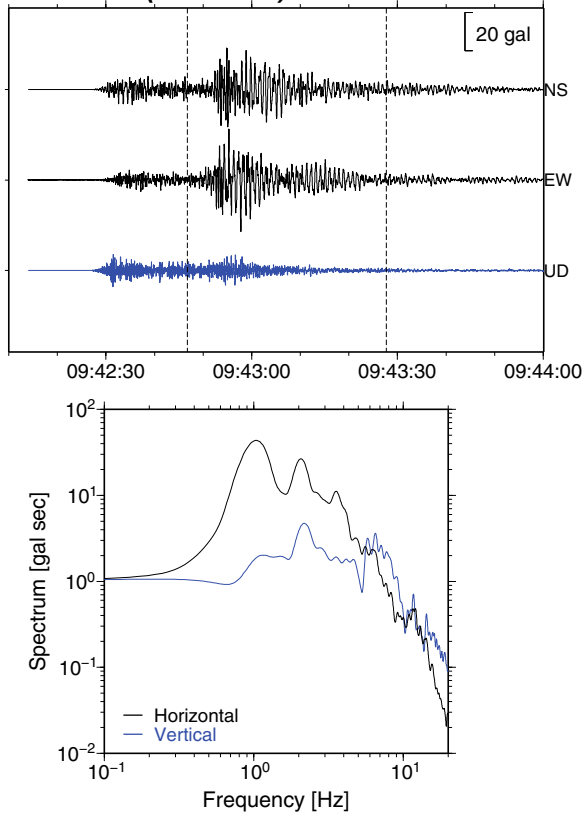
prediction experiments, we used almost the same data set as we used for site amplification estimation, except for the condition of maximum epicentral distance. An average difference in seismic intensity between two stations for scalar correction was calculated by at least seven earthquakes more than $100 \mathrm{~km}$ away from both stations. Comparison of two methods was made with the earthquakes in the same condition as calculating scalar correction values. Epicenters and magnitude-frequency distribution used for the seismic intensity prediction experiments are shown in Fig. 5. Number of earthquakes was 5972.

Figure 6a shows a map and relative site amplification factors for a surface station of TKCH01 (KiK-net Rikubetsu) and HKD088 (K-NET Rikubetsu), $5.3 \mathrm{~km}$ away. The site amplification characteristics calculated by spectral ratios showed a trough around $0.6 \mathrm{~Hz}$ in the horizontal component and around $1 \mathrm{~Hz}$ in the vertical component that was replicated by the site-correct digital filters (Fig. 6b).

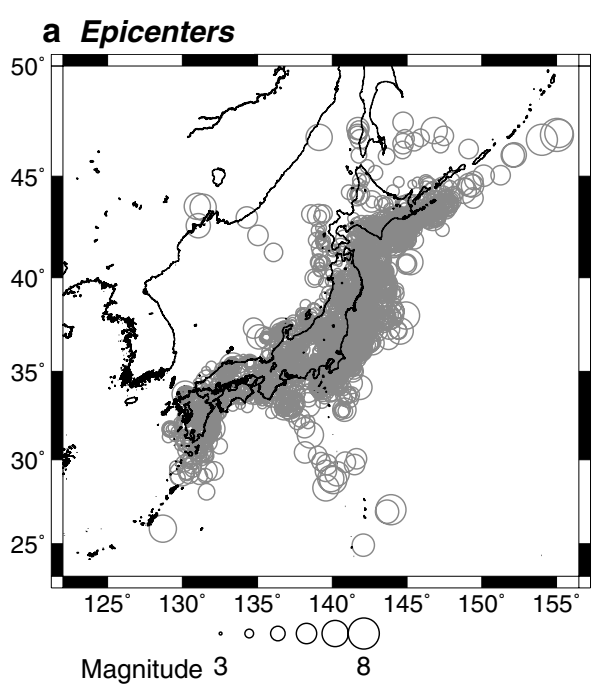

b Magnitude-frequency

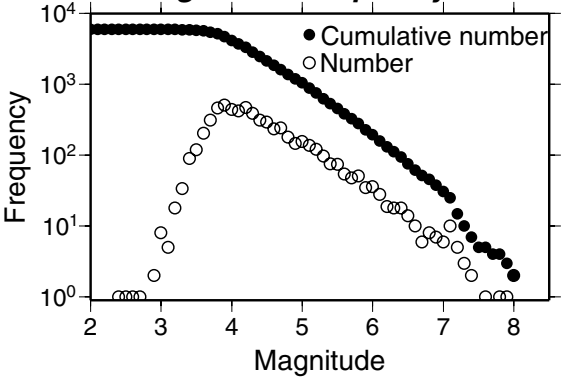

Fig. 5 a Epicenters and $\mathbf{b}$ magnitude-frequency relation (open circle for number and black for cumulative number) of earthquakes used for seismic intensity prediction experiment

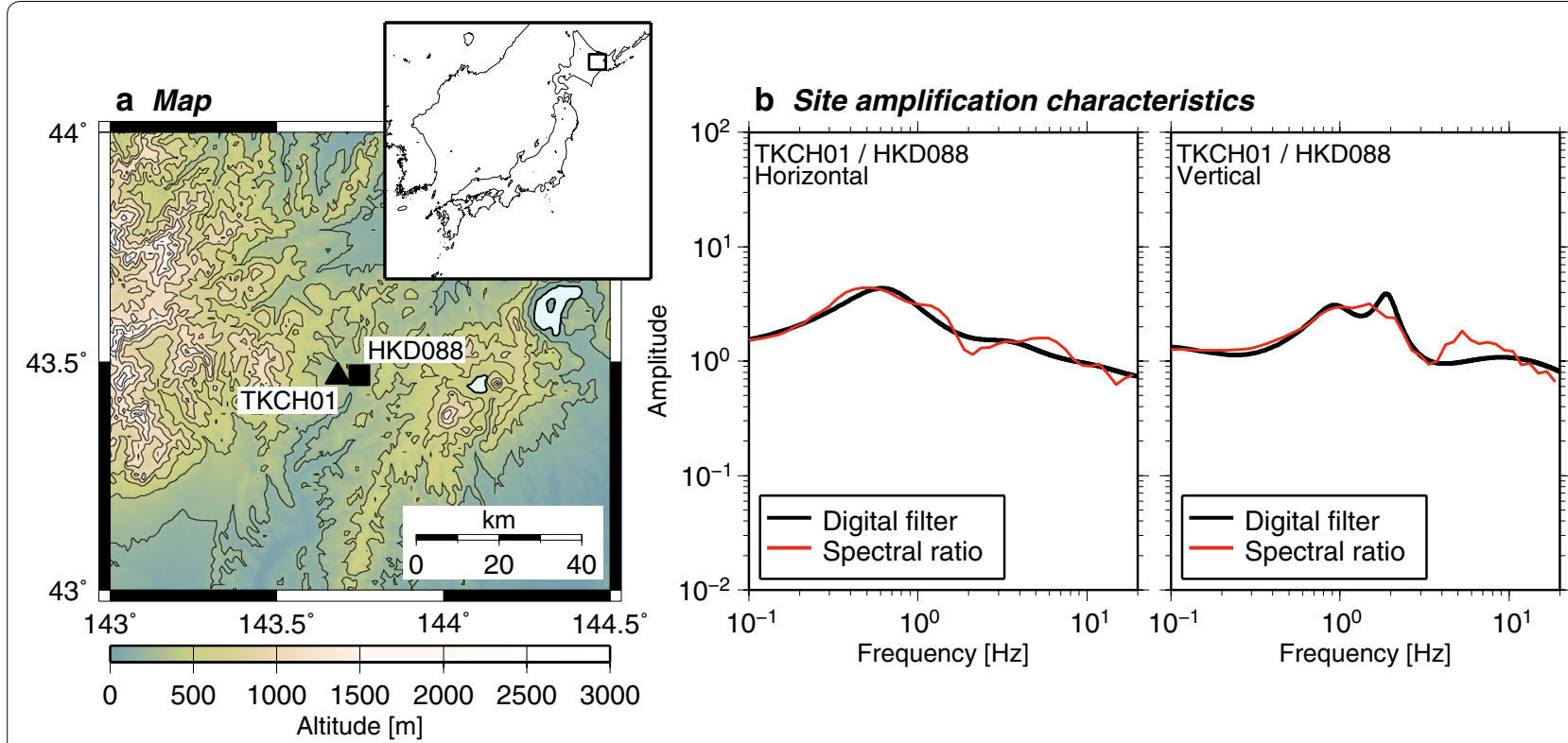

Fig. 6 a Map of stations TKCH01 (KiK-net Rikubetsu) and HKD088 (K-NET Rikubetsu). Contour interval is 200 m. b Relative site amplification factors between TKCH01 (surface) and HKD088 calculated by spectral ratio (red) and site-correct filters (black) 
Figure 7 shows the distribution of residuals (observed minus predicted value) of the seismic intensity predicted by both methods for each earthquakes recorded by stations TKCH01 (surface) and HKD088. The mean of residuals by scalar correction equals to zero, because we used the same waveform data set in both calculating average seismic intensity differences and predicting seismic intensity with scalar correction. The histograms of residuals and root mean square (RMS) of residuals clearly show that the frequency-dependent correction prediction worked better than the scalar correction prediction for this station pair. Interesting feature, azimuthal dependency of prediction residuals was found in the both prediction methods. We only point out two possibilities for this feature, and we do not discuss the causes in detail in this paper: One is the azimuthal dependency of site amplification and the other is the differences in source characteristics. Azimuthal dependency of site

\section{a Frequency correction prediction from TKCH01[A] to HKD088[]]}
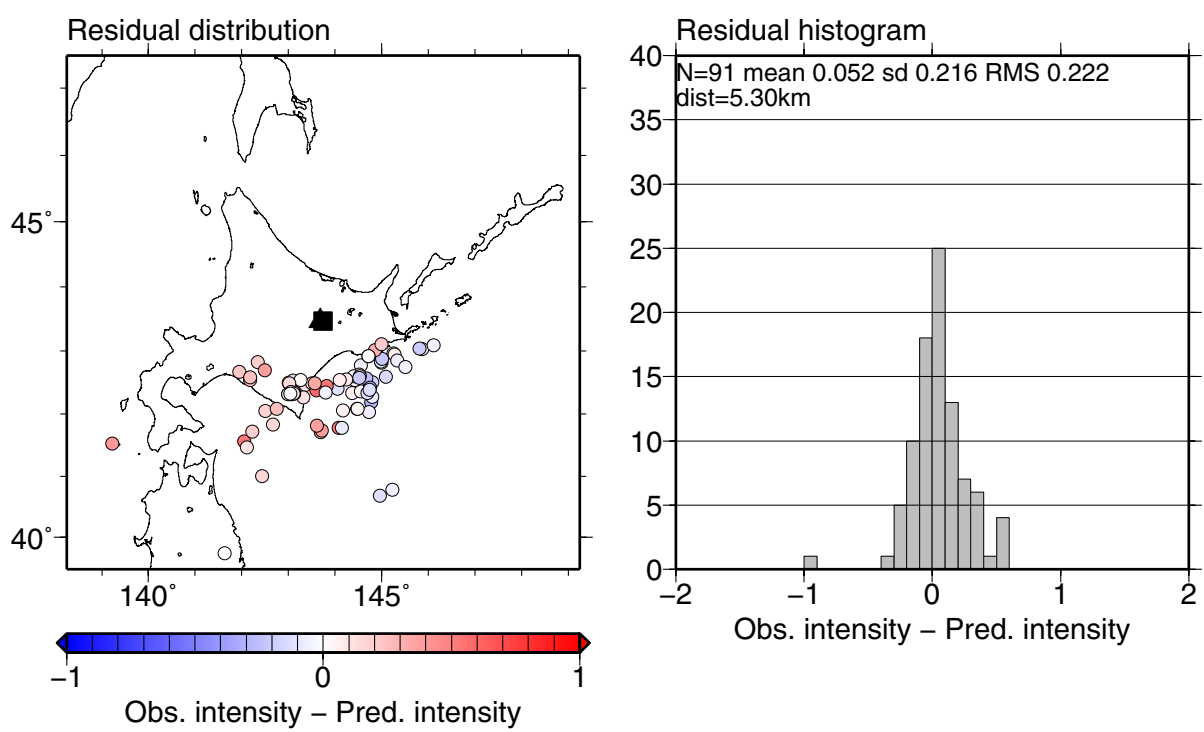

Obs. intensity - Pred. intensity

\section{b Scalar correction prediction from TKCH01[A] to HKD088[-]}

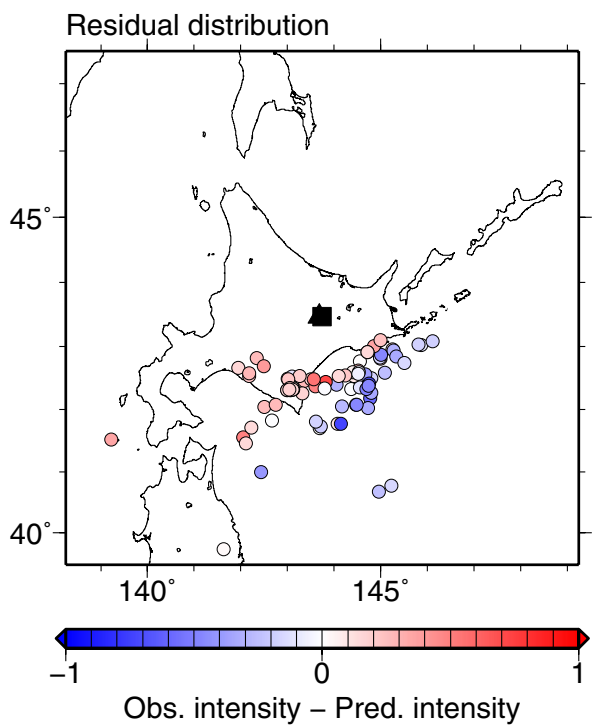

Residual histogram

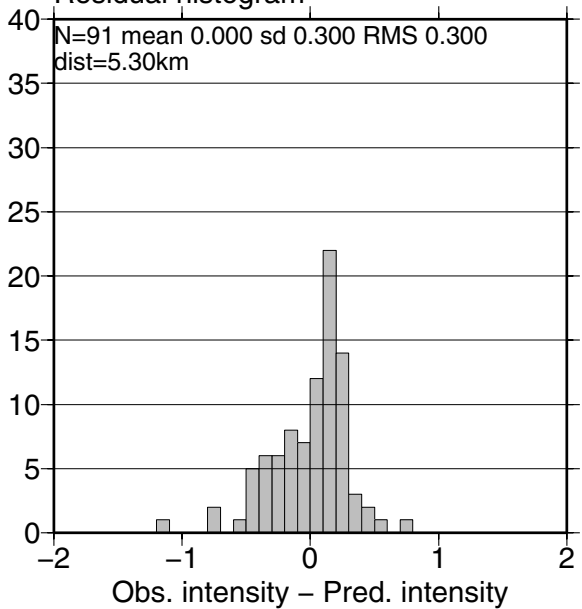

Obs. intensity - Pred. intensity

Fig. 7 Predicted intensity residuals of earthquakes (left panel) and histograms of residuals (right panel) for station pair TKCH01 (surface) and HKD088 after $\mathbf{a}$ frequency correction prediction and $\mathbf{b}$ scalar correction prediction 


\section{a Frequency correction prediction}

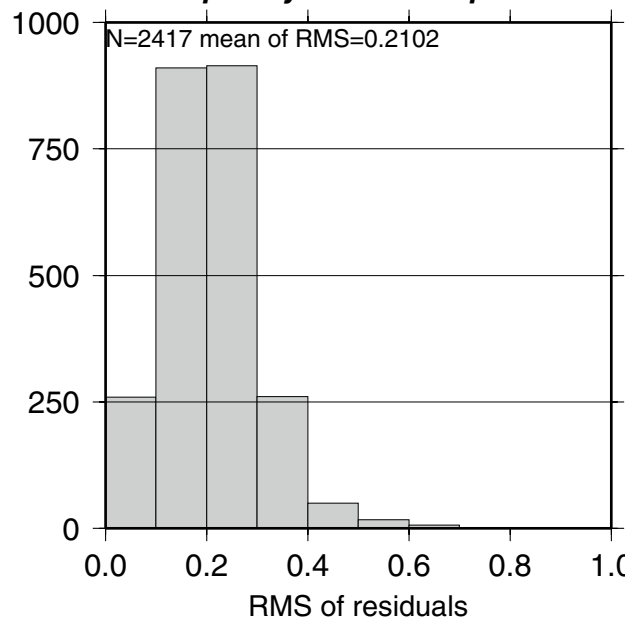

b Scalar correction prediction

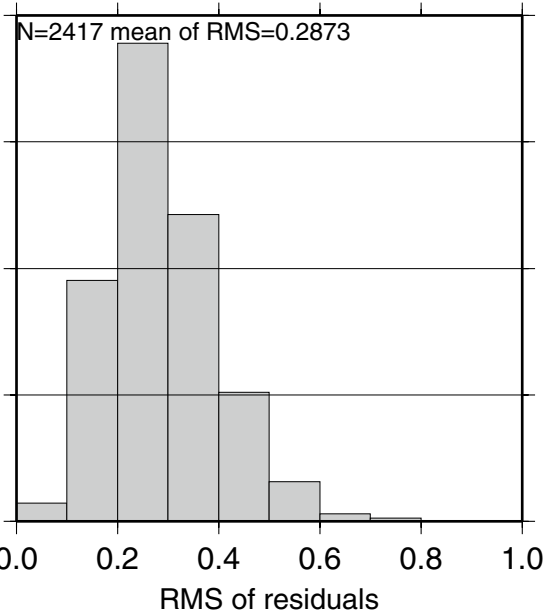

Fig. 8 Histograms of RMS of residuals for all station pairs separated by less than $10 \mathrm{~km}$ after $\mathbf{a}$ frequency correction and $\mathbf{b}$ scalar correction prediction

amplification affects both methods, while source characteristics affect scalar correction method. Future work is required to investigate the azimuthal dependency of prediction residuals in both methods.

When we compared histograms of RMS of residuals for all 2417 station pairs separated by less than $10 \mathrm{~km}$ (Fig. 8), the mean RMS from the frequency-dependent correction methods was about $27 \%$ smaller than that from the scalar correction method. Figure 9, showing the RMS histograms in three dimensions, indicates that both prediction methods worked well to some degree with the RMS residuals less than 0.5 and frequency-dependent correction sometimes worked worse than scalar correction. Nevertheless, prediction using frequency-dependent correction improved the RMS of prediction residuals in many cases.

\section{Discussion}

We showed that the frequency-dependent site amplification correction led to the accurate seismic intensity prediction. In the viewpoint of long lead time for EEW, the interstation distance of $10 \mathrm{~km}$ seems to be too short, and we should use station pair with longer interstation distance. At interstation distances larger than the value of $10 \mathrm{~km}$ we used, the source and path terms would surely have a greater influence on intensity predictions. We therefore evaluated the cases where interstation distances shorter than $20 \mathrm{~km}$ and shorter than $30 \mathrm{~km}$. Histograms of the resulting RMS of residuals are shown in Fig. 10. The mean RMS of residuals of both prediction methods becomes worse as the interstation distance increases, representing that the differences in seismic intensity between stations could not be explained by the difference

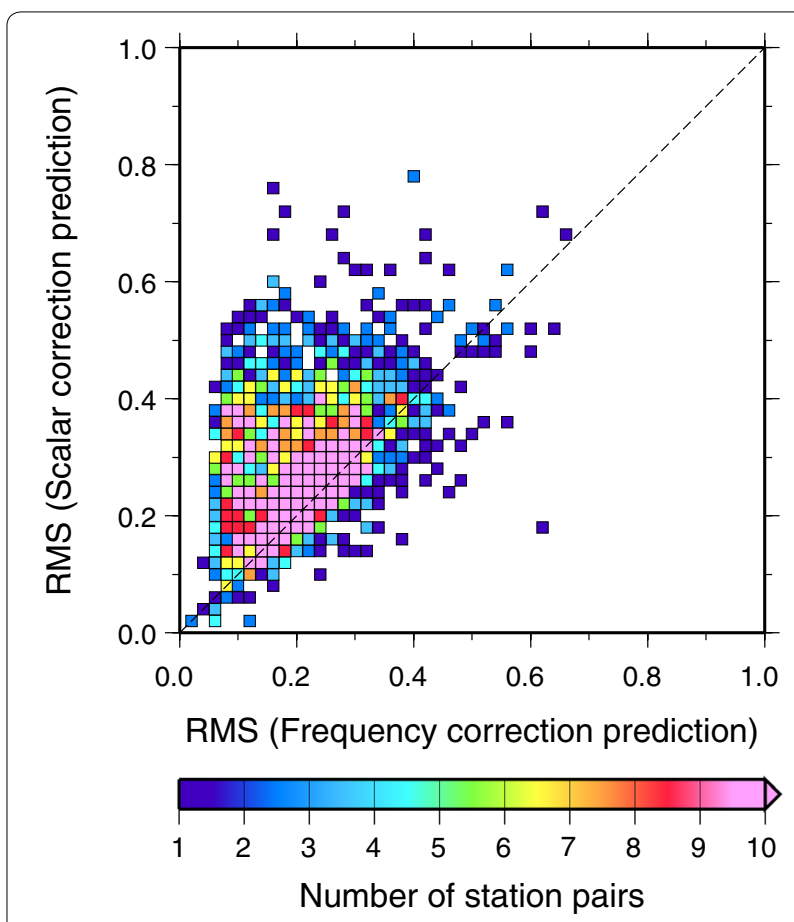

Fig. 9 Three-dimensional histogram of RMS residuals for all station pairs by less than $10 \mathrm{~km}$ after frequency correction and scalar correction. The number of station pairs was counted in bins with sides measuring 0.02

in site amplification term only, i.e., the effects of path and source term differences between two stations increased as the interstation distance increased. This fact suggests that the effects of path and source term are important for 


\section{a station distance: less than 20 km}

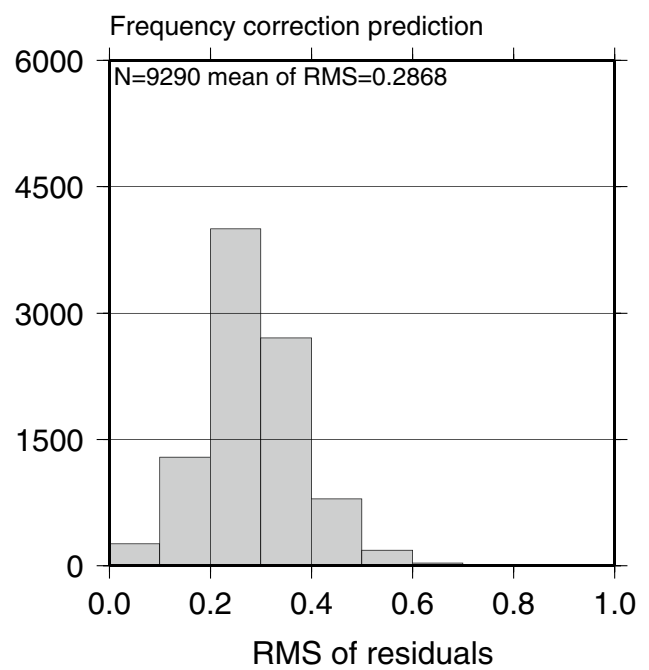

Scalar correction prediction

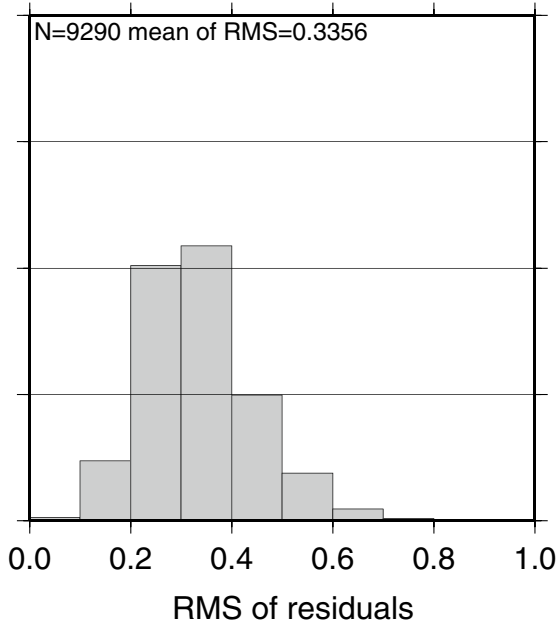

b station distance: less than $30 \mathrm{~km}$
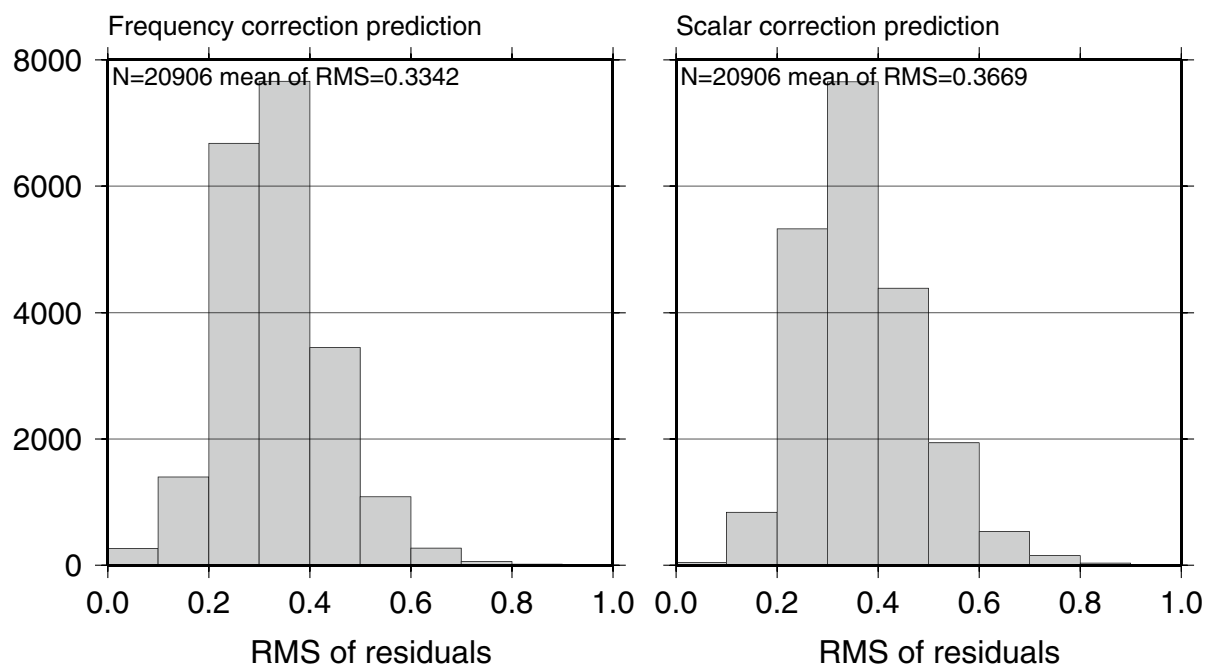

Fig. 10 Histograms of RMS of residuals for all station pairs separated by $\mathbf{a}$ less than $20 \mathrm{~km}$ and $\mathbf{b}$ less than $30 \mathrm{~km}$. Left side for frequency correction prediction and right side for scalar correction prediction

practical use of our seismic intensity prediction concept with long lead time where we should use station pair with long interstation distances. The advantages of frequencydependent correction become smaller as the interstation distance elongates, implying that the importance of frequency-dependent site amplification may be masked by the effects of path and source term. Detailed analysis of decomposition the effects of source, path, and site terms to the seismic intensity prediction will be future work.

Recently, Hoshiba and Aoki (2015) proposed numerical shake prediction method for EEW system. In their procedure, first current wavefield is estimated using data assimilation and then ground motion is predicted by solving a wave equation in real time with current wavefield as an initial condition. Same as our prediction concept, Hoshiba and Aoki (2015) aims to predict ground motion without any hypocentral parameters. Our prediction method assumes that the difference in seismic intensity between two stations is mainly caused by the difference in site amplification; however, numerical shake prediction method is based on the physics of wave propagation, so that effects of path term are included in their method. In addition, because the effect of seismic source should affect the amplitude distribution of current wavefield so that estimation of current wavefield incorporates the effect of source term. As a result, with the numerical 
shake prediction method, the accuracy of seismic intensity prediction will be improved even if the interstation distance becomes longer or epicentral distance becomes shorter. Site-correct filters estimated in this study are indispensable in the scheme of numerical shake prediction, as is shown by Hoshiba and Aoki (2015).

The improvement offered by frequency-dependent correction was not found in all cases. An example was the case of the station pair YMTH06 (surface sensor of KiK-net Takahata, target station) and YMT015 (K-NET Yonezawa, observation station), in which the site-correct filters closely approximated the observed spectral ratios (Fig. 11). However, although the standard deviation of residuals of frequency-dependent correction yielded a lower standard deviation of residuals than the scalar correction prediction, the mean of the residuals deviated from zero, leading to a large RMS value (Fig. 12). One of the possible reasons of this result is an azimuthal dependency of site amplification. Earthquakes in the southeastern region from both stations (left panel of Fig. 12a) had large residuals, causing the large RMS value. Figure 13 shows the observed spectral ratios of each earthquake between YMT015 and YMTH06 drawn in different colors corresponding to the backazimuth. Site-correct filters (Fig. 11b) reproduced the general characteristics of spectral ratios well (Fig. 13); however, if we check the observed spectral ratios carefully, there might be a weak azimuthal dependency around $1 \mathrm{~Hz}$ in horizontal component in observed spectral ratios. We did not take azimuthal dependency of site amplification factor into consideration in designing site-correct filters in this study. If we design multiple site-correct filters regarding the azimuthal dependency of site amplification, we would be able to predict seismic intensity more precisely. Other reason is the influence of smoothing the site amplification. Although observed spectral ratios of each earthquake had many peaks and troughs, site-correct filters did not represent such features (Fig. 13). The JMA seismic intensity is calculated from the peak value of the observed waveform envelope (JMA 1996; Hoshiba and Ozaki 2013). Site amplification correction with smoothed frequency characteristics (Figs. 11b, 13) might not reproduce the peak value of the envelope in the target station. More work in the future will be needed to reveal the relationship between the peak value of seismic waveforms and the frequency characteristics of both amplitudes and phases.

We have shown the importance of frequency-dependent site amplification term for ground motion (seismic intensity in this study) prediction. Because of dense seismic networks and highly active seismicity in Japan, we were able to estimate site amplification factor with simple assumptions in source and path terms. In other area with relatively sparse seismic networks and low seismicity, it would be able to estimate reliable site amplification factor if we adopt other noble method (e.g., coda normalization method (Phillips and Aki 1986; Takemoto et al. 2012) or generalized spectrum inversion, Kawase and Matsuo 2004; Nakano et al. 2015) and careful treatment of source term. Our intensity prediction methods, only correcting site amplification term, might also work well only with dense seismic network. In sparse seismic network, we have to consider the effect of path and source term if we would like to predict ground motion directly
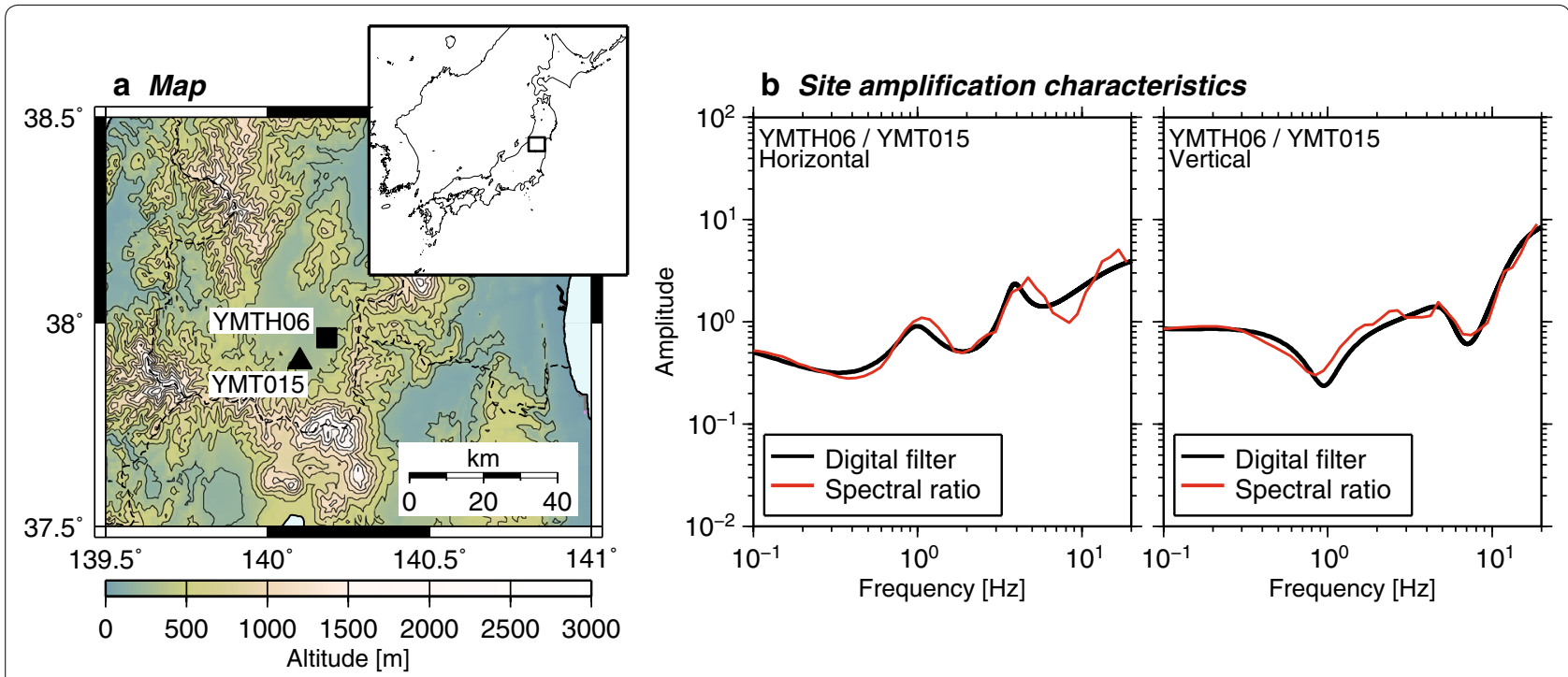

Fig. 11 a Map of stations YMT015 (K-NET Yonezawa) and YMTH06 (KiK-net Takahata). Contour interval is $200 \mathrm{~m}$. b Relative site amplification factors between YMT015 and YMTH06 (surface) calculated by spectral ratio (red) and site-correct filters (black) 


\section{a Frequency correction prediction from YMT015[A] to YMTH06[-]}
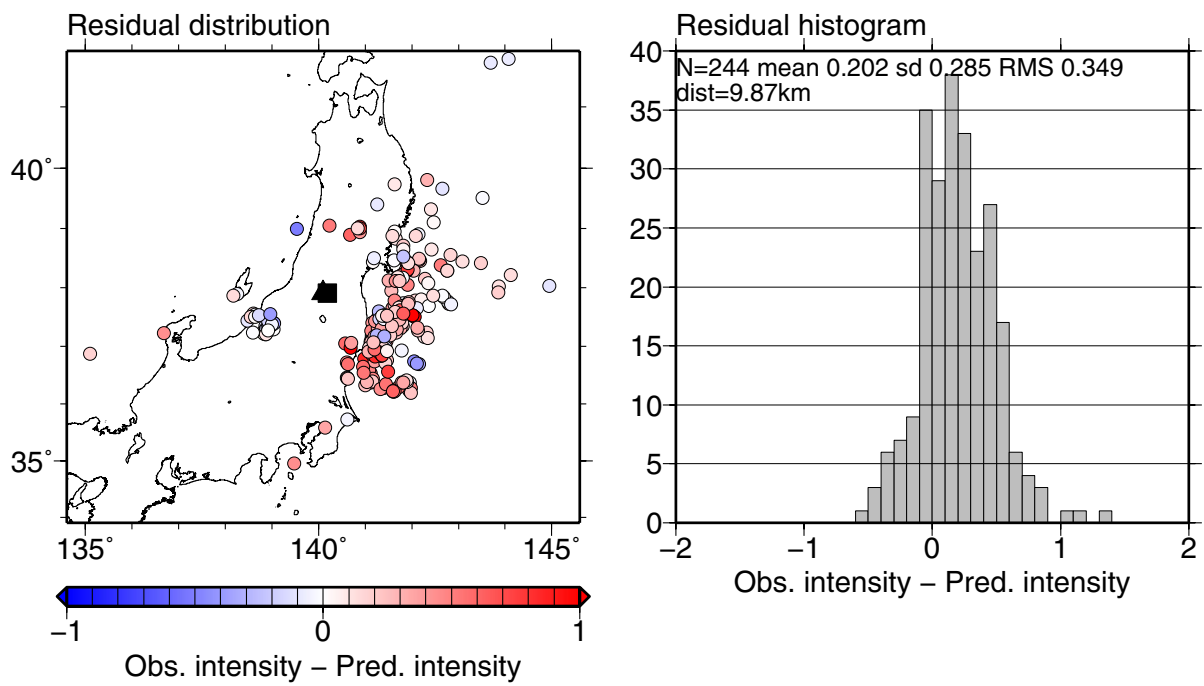

b Scalar correction prediction from YMT015[A] to YMTH06[-]

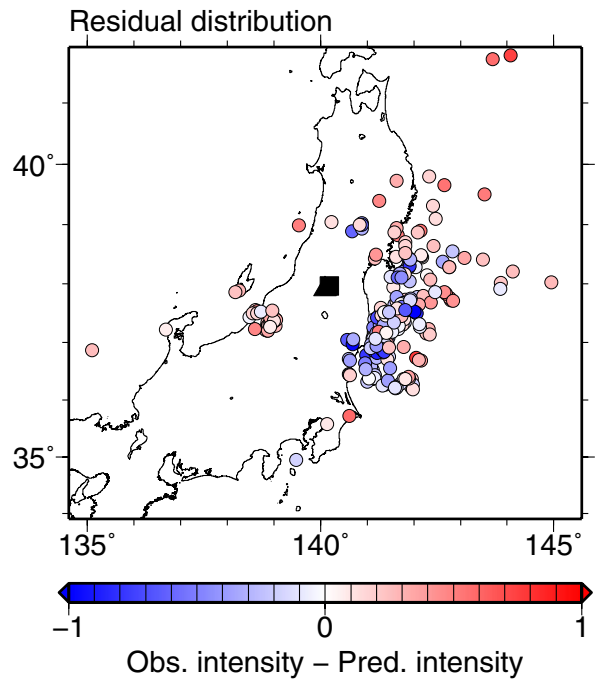

Residual histogram

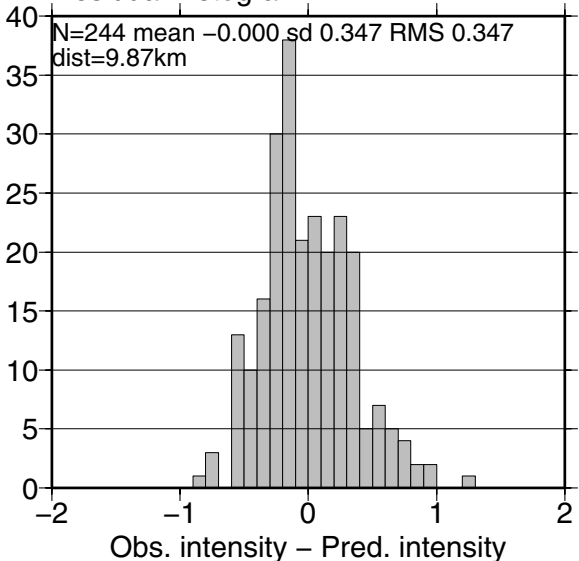

Obs. intensity - Pred. intensity

Fig. 12 Predicted intensity residuals of earthquakes (left panel) and histograms of residuals (right panel) for station pair YMT015 and YMTH06 (surface) after $\mathbf{a}$ frequency correction prediction and $\mathbf{b}$ scalar correction prediction

from observed ground motion. Numerical shake prediction scheme (Hoshiba and Aoki 2015) is one of the solutions for this issue. Appropriate parameter tuning in this scheme will lead to predict ground motion precisely even with relatively sparse seismic network.

\section{Conclusion}

We conducted experiments predicting seismic intensity at a station based on the data from an adjacent station, comparing two different methods, frequency-dependent correction and scalar correction, to correct relative site amplification factors. To estimate frequency-dependent relative site amplification factors, we calculated spectral ratios of direct $\mathrm{S}$-waves for many station pairs and solved simultaneous equations to acquire site amplification factors relative to a reference station. We then designed site-correct digital filters that approximated these site amplification characteristics of each station. Also, we calculated average differences in seismic intensity between two stations for scalar correction. In all but a few cases, seismic intensity prediction with frequency-dependent correction using site-correct filters worked better than prediction with scalar correction, showing the importance of considering the frequency characteristics of site 


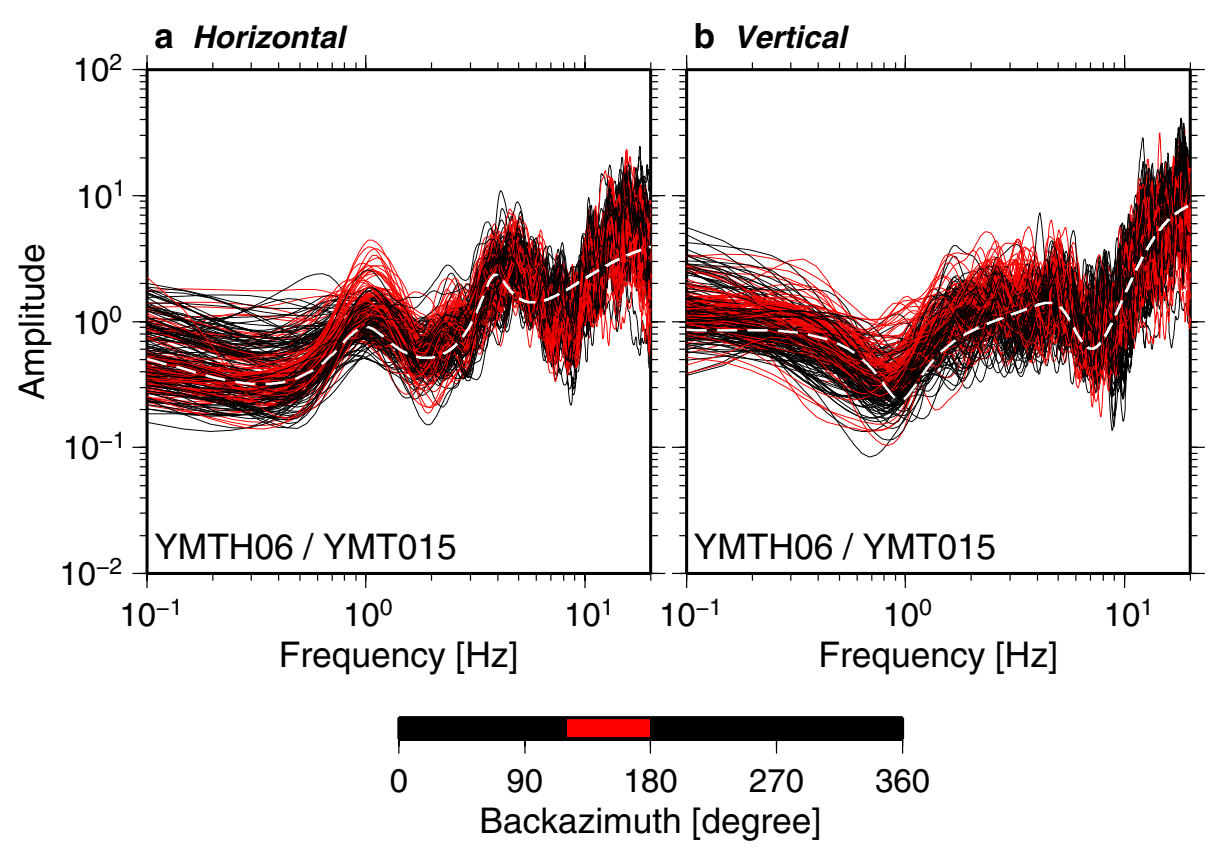

Fig. 13 a Horizontal component and $\mathbf{b}$ vertical component of observed spectral ratios of each earthquakes between YMT015 and YMTH06 (surface). Earthquakes with the backazimuth angle of 120-180 degree are plotted in red, while those with the other angle are in black. Frequency characteristics of site-correct filters are plotted in white broken lines

amplification in seismic intensity predictions. As interstation distance becomes longer, the differences between stations in the path and source term increase until the site amplification correction offers only a marginal advantage for seismic intensity prediction.

\section{Authors' contributions}

MO conducted the analysis and drafted the manuscript. SA wrote a program for site amplification estimation and conducted the initial analysis of seismic intensity prediction. $\mathrm{MH}$ made a program for designing filters and discussed about the results. All authors read and approved the final manuscript.

\section{Author details}

${ }^{1}$ Meteorological Research Institute, Japan Meteorological Agency, 1-1 Nagamine, Tsukuba, Ibaraki 305-0052, Japan. ${ }^{2}$ Seismology and Volcanology Department, Japan Meteorological Agency, 1-3-4 Otemachi, Chiyoda-ku, Tokyo 100-8122, Japan.

\section{Acknowledgements}

We used the waveform data from K-NET and KiK-net, which are operated by NIED. We thank all the personnel who maintain these strong-motion networks. We are grateful to anonymous reviewer and Matteo Picozzi for their helpful comments. Figures were drawn by Generic Mapping Tools (Wessel and Smith 1998). Part of this study was supported by KAKENHI Grant Number 25282114 from the Japan Society for the Promotion of Science.

\section{Competing interests}

The authors declare that they have no competing interests.

\section{Appendix: Influence of radiation pattern}

In "Estimation of frequency-dependent site amplification factors" section, we assumed that radiation pattern of earthquake $k$ was common to stations $i$ and $j$ if we picked up the interstation distance was less than $30 \mathrm{~km}$ and epicentral distance was longer than $100 \mathrm{~km}$; however, the assumption might not be valid in some cases. We show the influence of the radiation pattern in this section. Figure 14 shows cumulative histogram of azimuthal difference in each station pair with earthquakes shown in Fig. 1. In our data set, most of the azimuthal difference between each station pair is less than 10 degree. Maximum azimuthal difference is about $17^{\circ}$ for interstation distance of $30 \mathrm{~km}$.

Radiation pattern coefficients for P, SH, and SV wave, $R_{p}, R_{S H}$, and $R_{S V}$, are expressed by the following equations (e.g., Aki and Richards 2002):

$$
\begin{aligned}
R_{p}\left(\theta, i_{h}\right)= & \cos \lambda \sin \delta \sin ^{2} i_{h} \sin 2\left(\theta-\theta_{s}\right) \\
- & \cos \lambda \cos \delta \sin 2 i_{h} \cos \left(\theta-\theta_{s}\right) \\
+ & \sin \lambda \sin 2 \delta\left(\cos ^{2} i_{h}-\sin ^{2} i_{h} \sin ^{2}\left(\theta-\theta_{s}\right)\right) \\
+ & \sin \lambda \cos 2 \delta \sin 2 i_{h} \sin \left(\theta-\theta_{s}\right) \\
R_{S H}\left(\theta, i_{h}\right)= & \cos \lambda \cos \delta \cos i_{h} \sin \left(\theta-\theta_{s}\right) \\
& +\cos \lambda \sin \delta \sin i_{h} \cos 2\left(\theta-\theta_{s}\right) \\
& +\sin \lambda \cos 2 \delta \cos i_{h} \cos \left(\theta-\theta_{s}\right) \\
& -0.5 \sin \lambda \sin 2 \delta \sin i_{h} \sin 2\left(\theta-\theta_{s}\right), \\
R_{S V}\left(\theta, i_{h}\right)= & \sin \lambda \cos 2 \delta \cos 2 i_{h} \sin \left(\theta-\theta_{s}\right) \\
& -\cos \lambda \cos \delta \cos 2 i_{h} \cos \left(\theta-\theta_{s}\right) \\
& +0.5 \cos \lambda \sin \delta \sin 2 i_{h} \sin 2\left(\theta-\theta_{s}\right) \\
& -0.5 \sin \lambda \sin 2 \delta \sin 2 i_{h}\left(1+\sin ^{2}\left(\theta-\theta_{s}\right)\right),
\end{aligned}
$$




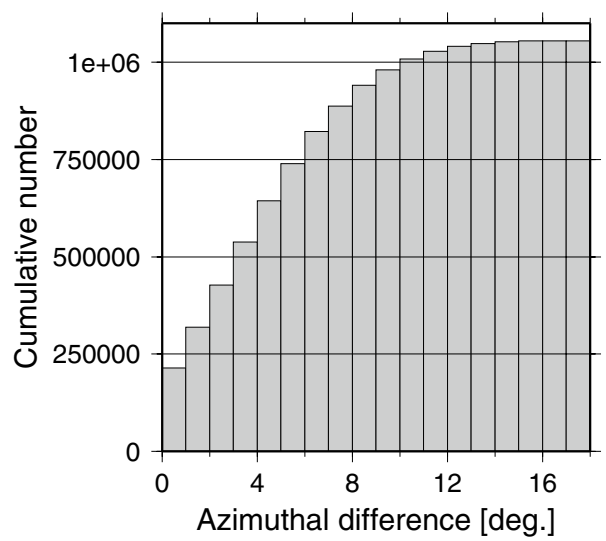

Fig. 14 Cumulative histograms of azimuthal difference between each station pair for common earthquakes shown in Fig. 1

where $\theta$ and $i_{h}$ are azimuth and take-off angle from source to receiver and $\theta_{s}, \delta, \lambda$ are strike, dip, and rake of the fault, respectively. We calculated the ratio of $\mathrm{SH}$ wave radiation pattern coefficients for two cases: (1) Epicentral distance $(100 \mathrm{~km})$ was the same and azimuthal difference was $\delta \theta$ for a station pair (Fig. 15a) and (2) azimuth from source to stations was the same, and interstation distance caused difference in epicentral distance for a station pair (Fig. 15b). We assumed strike-slip earthquake of $\theta_{s}=0[\mathrm{deg}], \delta=90[\mathrm{deg}], \lambda=0[\mathrm{deg}]$ at $10 \mathrm{~km}$ depth. Takeoff angle was calculated based on the JMA2001 velocity structure (Ueno et al. 2002). We calculated the ratios for two cases, $\delta \theta=10[\mathrm{deg}]$ and $\delta \theta=17[\mathrm{deg}]$ for case 1 . In case 1 , ratio of radiation pattern coefficients shows periodic behavior with four peaks and troughs (right panel of Fig. 15a). Most of the ratio value lies between 0.5 and 2 especially for $\delta \theta=10[\mathrm{deg}]$. Because of its periodic behavior, influence of radiation pattern would be suppressed if we take an average for many earthquakes randomly distributed. On the other hand, for case 2 (right panel of Fig. 15b), ratio is almost 1 so that difference in epicentral distance can be neglected. In our site amplification estimation, observations (right-hand side of Eq. 7) were averaged using at least seven earthquakes so that influence of radiation pattern was reduced. We point out that the careful treatment of radiation pattern in spectral ratio calculation may lead to more precise estimation of site amplification factor. a case 1
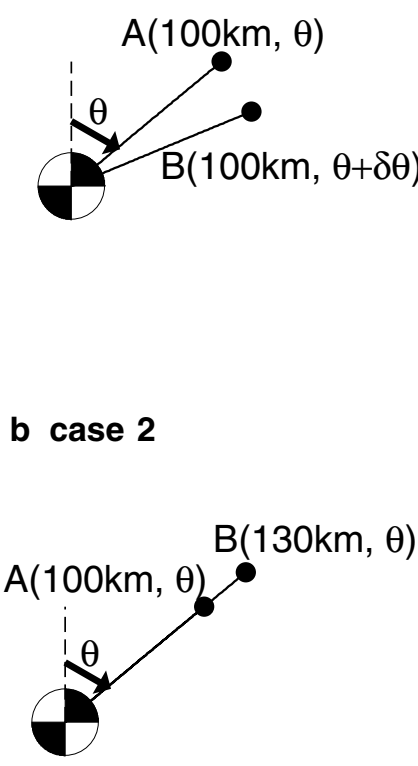
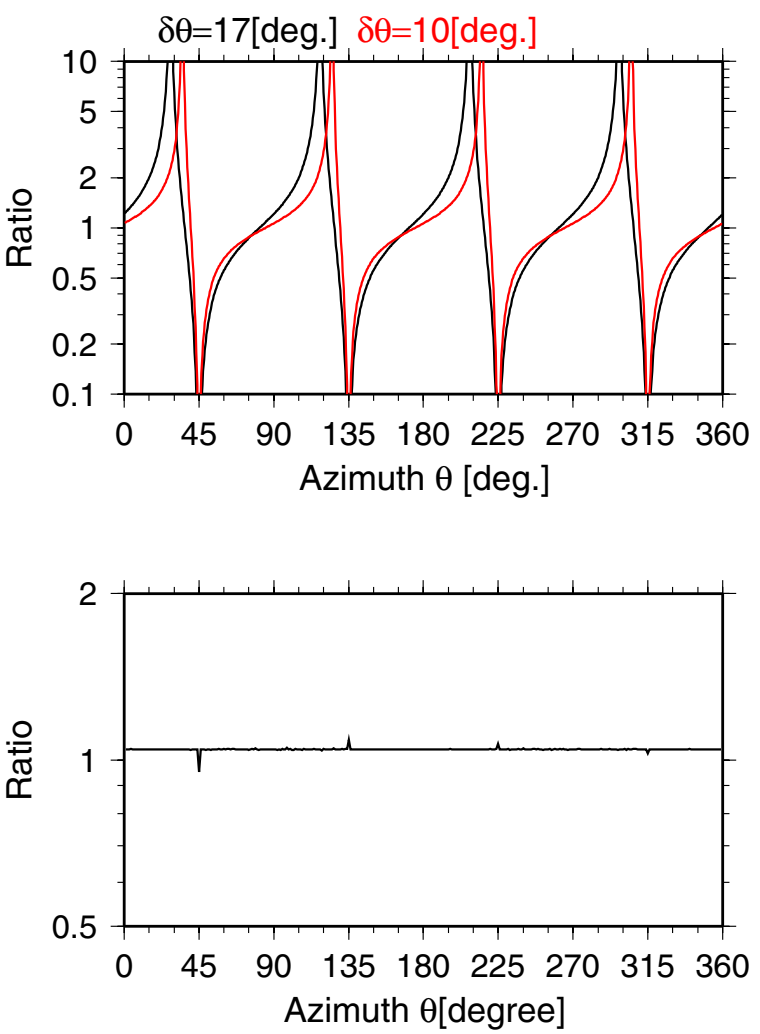

Fig. 15 Theoretical radiation pattern coefficients ratio for $\mathbf{a}$ case 1: interstation distance causes azimuthal difference and $\mathbf{b}$ case 2: interstation distance causes epicentral distance difference. For $\mathbf{a}$, black line means azimuthal difference $(\delta \theta)$ is $17^{\circ}$, while red line means azimuthal difference is $10^{\circ}$ 
Received: 19 February 2016 Accepted: 6 May 2016

Published online: 21 May 2016

\section{References}

Aki K, Richards PG (2002) Quantitative seismology, 2nd edn. University Science Books, Sausalito

Böse M, Heaton T, Hauksson E (2012) Real-time finite fault rupture detector (FinDer) for large earthquakes. Geophys J Int 191:803-812. doi:10.1111/j.1365-246X.2012.05657.x

Colombelli S, Allen R, Zollo A (2013) Application of real-time GPS to earthquake early warning in subduction and strike-slip environments. J Geophys Res 118:3448-3461. doi:10.1002/jgrb.50242

Grapenthin R, Johanson IA, Allen R (2014) Operational real-time GPS-enhanced earthquake early warning. J Geophys Res 119:7944-7965. doi:10.1002/2 014JB011400

Hata Y, Nozu A, Ichii K (2011) Practical method to estimate strong ground motions after an earthquake, based on site amplification and phase characteristics. Bull Seismol Soc Am 101:688-700. doi:10.1785/0120100142

Hirose F, Miyaoka K, Hayashimoto N, Yamazaki T, Nakamura M (2011) Outline of the 2011 off the Pacific coast of Tohoku Earthquake $\left(M_{w} 9.0\right)$ - seismicity: foreshocks, mainshock, aftershocks, and induced activity. Earth Planets space 63:513-518. doi:10.5047/eps.2011.05.019

Hoshiba M (2013a) Real-time prediction of ground motion by KirchhoffFresnel boundary integral equation method: extended front detection method for earthquake early warning. J Geophys Res Solid Earth 118:1038-1050. doi:10.1002/jgrb.50119

Hoshiba M (2013b) Real-time correction of frequency-dependent site amplification factors for application to earthquake early warning. Bull Seismol Soc Am 103:3179-3188. doi:10.1785/0120130060

Hoshiba M, Aoki S (2015) Numerical shake prediction for earthquake early warning: data assimilation, real-time shake mapping, and simulation of wave propagation. Bull Seismol Soc Am 105:1324-1338. doi:10.1785/0120140280

Hoshiba M, Ozaki T (2013) Earthquake early warning and tsunami warning of the Japan Meteorological Agency, and their performance in the 2011 off the Pacific Coast of Tohoku Earthquake (Mw 90). In: Zschau J, Wenzel F (eds) Early warning for geological disasters scientific methods and current practice. Springer, Heidelberg, pp 1-28. doi:10.1007/978-3-642-12233-0_1

Hoshiba M, Iwakiri K, Hayashimoto N, Shimoyama T, Hirano K, Yamada Y, Ishigaki Y, Kikuta H (2011) Outline of the 2011 off the Pacific coast of Tohoku Earthquake $\left(M_{w} 9.0\right)$ - earthquake early warning and observed seismic intensity. Earth Planets Space 63:547-551. doi:10.5047/eps.2011.05.031

Ikeura T, Kato K (2011) Evaluation of relative site amplification factors by combining average spectral ratios of strong ground motions simultaneously observed at adjacent two sites - application to K-NET and KiK-net sites in the Pacific Coast Side of the Tohoku district. J Jpn Assoc Earthq Eng 11:4_48-4_67. doi:10.5610/jaee.11.4_48 (in Japanese with English abstract)

Japan Meteorological Agency (JMA) (1996) Seismic intensity. Gyosei, Tokyo (in Japanese)
Kawase H, Matsuo H (2004) Separation of source, path, and site effects based on the observed data by K-NET, KiK-net, and JMA strong motion network. J Jpn Assoc Earthq Eng 4(1):33-52. doi:10.5610/jaee.4.33 (in Japanese with English abstract)

Kunugi T, Aoi S, Nakamura H, Suzuki W, Morikawa N, Fujiwara H (2013) An improved approximating filter for real-time calculation of seismic intensity. Zisin (J Seismol Soc Jpn, 2nd ser.) 65:223-230. doi:10.4294/ zisin.65.223 (in Japanese with English abstract and figure captions)

Midorikawa S (2009) Ground motion attenuation relations. Zisin (J Seismol Soc Jpn, 2nd ser.) 61:S471-S477. doi:10.4294/zisin.61.471 (in Japanese with English abstract and figure captions)

Nakano K, Matsushima S, Kawase H (2015) Statistical properties of strong ground motions from the generalized spectral inversion of data observed by K-NET, in Japan. Bull Seismol Soc Am 105(5):2662-2680. doi:10.1785/0120140349

Nozu A, Nagao T, Yamada M (2007) Site amplification factors for strongmotion sites in japan based on spectral inversion technique and their use for strong-motion evaluation. J Jpn Assoc Earthq Eng 7(2):215-234. doi:10.5610/jaee.7.2_215 (in Japanese with English abstract)

Okada Y, Kasahara K, Hori S, Obara K, Sekiguchi S, Fujiwara H, Yamamoto A (2004) Recent progress of seismic observation networks in Japan- Hinet, F-net, K-NET and KiK-net. Earth Planets Space 56:BF03353076. doi:10.1186/BF03353076

Phillips WS, Aki K (1986) Site amplification of coda waves from local earthquakes in central California. Bull Seismol Soc Am 76:627-648

Satoh T, Kawase H (2009) Site responses of sediments. Zisin (J Seismol Soc Jpn, 2nd ser.), 61:S455-S470. doi:10.4294/Zisin.61.455 (in Japanese with English abstract and figure captions)

Satoh T, Kawase H, Sato T (1994) Statistical spectral characteristics for engineering bedrock waves in which local site effects of surface geology are removed. J Struct Constr Eng AIJ 462:79-89 (in Japanese)

Takemoto T, Furumura T, Saito T, Maeda T, Noguchi S (2012) Spatial- and frequency-dependent properties of site amplification factors in Japan derived by the coda normalization method. Bull Seismol Soc Am 102:1462-1476. doi:10.1785/0120110188

Tamaribuchi K, Yamada M, Wu S (2014) A new approach to identify multiple concurrent events for improvement of earthquake early warning. Zisin ( $\mathrm{J}$ Seismol Soc Jpn, 2nd ser.) 67:41-55. doi:10.4294/zisin.67.41 (in Japanese with English abstract and figure captions)

Ueno H, Hatekeyama S, Aketagawa T, Funasaki J, Hamada N (2002) Improvement of hypocenter determination procedures in the Japan Meteorological Agency. Q J Seismol 65:123-134 (in Japanese)

Wenzel F, Zschau J (eds.) (2014) Early warning for geological disasters scientific methods and current practice. Springer, Heidelberg. doi:10.1007/978-3-642-12233-0

Wessel P, Smith WHF (1998) New, improved version of the generic mapping tools released. EOS Trans AGU 79:579

Wu S, Yamada M, Tamaribuchi K, Beck JL (2014) Multi-events earthquake early warning algorithm using a Bayesian approach. Geophys J Int 200:791808. doi:10.1093/gji/ggu437

\section{Submit your manuscript to a SpringerOpen ${ }^{\circ}$ journal and benefit from:}

- Convenient online submission

- Rigorous peer review

- Immediate publication on acceptance

- Open access: articles freely available online

- High visibility within the field

- Retaining the copyright to your article

Submit your next manuscript at springeropen.com 